\title{
$\alpha$-Retinol and 3,4-didehydroretinol support growth in rats when fed at equimolar amounts and $\alpha$-retinol is not toxic after repeated administration of large doses
}

\author{
Napaporn Riabroy, Joseph T. Dever and Sherry A. Tanumihardjo* \\ Interdepartmental Graduate Program in Nutritional Sciences, Department of Nutritional Sciences, \\ University of Wisconsin-Madison, 1415 Linden Drive, Madison, WI 53706, USA \\ (Submitted 9 July 2013 - Final revision received 7 October 2013 - Accepted 9 October 2013 - First published online 13 December 2013)
}

\section{Abstract}

Dietary $\alpha$-carotene is present in oranges and purple-orange carrots. Upon the central cleavage of $\alpha$-carotene in the intestine, $\alpha$-retinal and retinal are formed and reduced to $\alpha$-retinol $(\alpha \mathrm{R})$ and retinol. Previous reports have suggested that $\alpha \mathrm{R}$ has $2 \%$ biopotency of all-trans-retinyl acetate due in part to its inability to bind to the retinol-binding protein. In the present work, we carried out three studies. Study 1 re-determined $\alpha$ R's biopotency compared with retinol and 3,4-didehydroretinol in a growth assay. Weanling rats $(n$ 40) were fed a vitamin A-deficient diet for 8 weeks, divided into four treatment groups ( $n$ 10/group) and orally dosed with $50 \mathrm{nmol} / \mathrm{d}$ retinyl acetate $(14.3 \mu \mathrm{g}$ retinol), $\alpha$-retinyl

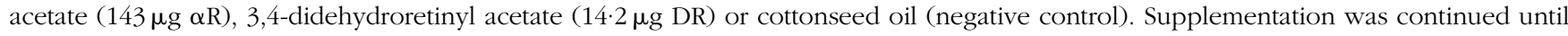
the control rats exhibited deficiency signs 5 weeks after the start of supplementation. Body weights and AUC values for growth response revealed that $\alpha \mathrm{R}$ and DR had 40-50 and 120-130\% bioactivity, respectively, compared with retinol. In study 2, the influence of $\alpha \mathrm{R}$ on liver $\mathrm{ROH}$ storage was investigated. The rats $(n 40)$ received $70 \mathrm{nmol}$ retinyl acetate and $0,17.5,35$ or $70 \mathrm{nmol} \alpha$-retinyl acetate daily for 3 weeks. Although liver retinol concentrations differed among the groups, $\alpha \mathrm{R}$ did not appreciably interfere with retinol storage. In study 3 , the accumulation and disappearance of $\alpha \mathrm{R}$ over time and potential liver pathology were determined. The rats $(n 15)$ were fed $3 \cdot 5 \mu \mathrm{mol} / \mathrm{d}$ $\alpha$-retinyl acetate for $21 \mathrm{~d}$ and the groups were killed at 1-, 2- and 3-week intervals. No liver toxicity was observed. In conclusion, $\alpha \mathrm{R}$ and didehydroretinol are more biopotent than previously reported at sustained equimolar dosing of $50 \mathrm{nmol} / \mathrm{d}$, which is an amount of retinol known to keep rats in vitamin A balance.

\section{Key words: $\boldsymbol{\alpha}$-Carotene: Bioactivities: Carrots: Vitamin $\mathbf{A}_{2}$}

Studies conducted in the 1950s suggested that $\alpha$-retinol $(\alpha \mathrm{R})$ (Fig. 1) is a biologically inactive form of vitamin $\mathrm{A}$, with approximately $2 \%$ biopotency being reported by comparing the results obtained in the rat growth and liver storage bioassays of the geometric isomers of vitamin A aldehyde with the US Pharmacopeia Vitamin A Reference Standard ${ }^{(1)}$. Another study reported 2.6\% bioactivity ${ }^{(2)}$, and Sneider et al. ${ }^{(3)}$ confirmed the lack of bioactivity, but suggested that $\alpha \mathrm{R}$ has partial vitamin A function. On more than one occasion, $\alpha$ R's lack of bioactivity was eloquently discussed by Pitt ${ }^{(4-6)}$. In 1969 , it was concluded that $\alpha \mathrm{R}$ had only $2 \cdot 1 \%$ of the activity of retinol (ROH) when assayed for growth-promoting activity in rats ${ }^{(6)}$. $\alpha \mathrm{R}$ has been shown to be very effective at inducing signs of hypervitaminosis A in both in vitro and in vivo models ${ }^{(7)}$. On the other hand, Shantz \& Brinkman ${ }^{(8)}$ demonstrated that 3,4-didehydroretinol (DR; vitamin $A_{2}$ ), which is the predominant form of vitamin $A$ in some freshwater fish, has $40 \%$ biological activity compared with $\mathrm{ROH}$ (vitamin $\mathrm{A}_{1}$ ). Methods to quantify and selectively determine analogue concentrations in tissues were not available when these studies were carried out. A more recent study has quantified $\alpha \mathrm{R}$ using HPLC after $\alpha$-carotene dosing in gerbils and found significant liver $\alpha \mathrm{R}$ storage ${ }^{(9)}$. Therefore, it was hypothesised that $\alpha \mathrm{R}$ could be used as a chylomicron tag as it appeared to be sequestered in the liver.

The difference between the biological activity of $\alpha \mathrm{R}$ and that of DR can be partially explained by the inability of $\alpha R$ compared with the ability of DR to bind to the retinol-binding protein (RBP), the specific carrier protein of ROH. RBP is synthesised by hepatic parenchymal cells as a $24 \mathrm{kDa}$ precursor, which is then converted to the RBP by the co-translational removal of a $3.5 \mathrm{kDa}$ polypeptide ${ }^{(10)}$. This protein product is called apo-RBP and holo-RBP when complexed with ROH or an analogue ${ }^{(11)}$. Moreover, DR is carried by the retinol transporter from the intestine at the same rate as $\mathrm{ROH}^{(12)}$. In 1975, Muhilal \& Glover ${ }^{(13)}$ tested the binding affinity of ROH and its analogues to the RBP. Unlike ROH, $\alpha \mathrm{R}$ failed to bind in vitro with apo-RBP, but DR did bind at a slower saturation time than $\mathrm{ROH}$ did. As a result, they suggested that the fission

Abbreviations: $\alpha \mathrm{R}, \alpha$-retinol; DR, 3,4-didehydroretinol; RBP, retinol-binding protein; ROH, retinol; UW, University of Wisconsin.

*Corresponding author: S. A. Tanumihardjo, fax +1608262 5860, email sherry@nutrisci.wisc.edu 
<smiles>CC1=C(/C=C/C(C)=C/C=C/C(C)=C/C=C/C=C(C)/C=C/C=C(C)/C=C/C2=C(C)CCCC2(C)C)C(C)(C)CCC1</smiles><smiles>CC1=CCCC(C)(C)C1/C=C/C(C)=C/C=C/C(C)=C/C=C/C=C(C)/C=C/C=C(C)/C=C/C1=C(C)CCCC1(C)C</smiles>

(c)<smiles>CC1=C(/C=C/C(C)=C/C=C/C(C)=C/C=C/C(C)O)C(C)(Cl)CCC1</smiles>

(d)<smiles>CC1=C(/C=C/C(C)=C/C=C/C(C)=C/CO)C(C)(Cl)CCC1</smiles>

(e)<smiles>CC1=CCCC(C)(Cl)C1/C=C/C(C)=C/C=C/C(C)=C/CO</smiles>

(f)<smiles>CC1=C(/C=C/C(C)=C/C=C/C(C)=C/CO)C(C)(Br)CC=C1</smiles>

Fig. 1. Chemical structures of (a) $\beta$-carotene, (b) $\alpha$-carotene, (c) C23 alcohol (internal standard; $\beta$-apo-carotenol), (d) retinol, (e) $\alpha$-retinol and (f) 3,4-didehydroretinol.

of the ring as in $\gamma$-retinol or changing the double bond from the 5,6-position (in $\beta$-retinol) to the 4,5-position as in $\alpha \mathrm{R}$ prevents the compound from binding to the RBP.

These discoveries are consistent with the findings of a study carried out by Tanumihardjo \& Howe ${ }^{(9)}$, who found that $\alpha \mathrm{R}$ is not present in the serum of gerbils fed $\alpha$-carotene, even though abundant amounts are present in the liver. Liver $\alpha \mathrm{R}$ concentration was found to be very similar to the difference in liver $\mathrm{ROH}$ concentrations of the $\alpha$-carotene and control groups, consistent with the central cleavage of $\alpha$-carotene in the intestinal brush border. In addition, $\alpha$-carotene may have a negative effect on the absorption of $\beta$-carotene in rats ${ }^{(14)}$. In rats fed a mixture of $\alpha$-carotene and $\beta$-carotene (1:2), liver $\mathrm{ROH}$ stores have been shown to be decreased compared with those fed $\beta$-carotene alone ${ }^{(14)}$. This suggests a potential interaction or competition between $\alpha \mathrm{R}$ and $\mathrm{ROH}$, but the degree and site of interaction have not been clearly defined.

In the present study, we carried out three studies in rats. In study 1, we determined the biopotency of $\alpha \mathrm{R}$ and $\mathrm{DR}$ compared with that of $\mathrm{ROH}$ in a controlled experiment where liver reserves could be accurately quantified with HPLC and $\mathrm{ROH}$ fed at a concentration known to keep rats in vitamin A balance, i.e. $50 \mathrm{nmol} / \mathrm{d}^{(15)}$. In study 2, we investigated the influence of $\alpha \mathrm{R}$ on liver $\mathrm{ROH}$ storage during graded feeding of $\alpha \mathrm{R}$ to the rats while equalising the amounts of $\mathrm{ROH}$ across the treatment groups at a level higher than that used in study 1 to allow for some ROH storage. Therefore, the overall influence of physiologically graded doses of $\alpha \mathrm{R}$ on the uptake and storage of $\mathrm{ROH}$ could be determined. In study 3, we determined the accumulation and disappearance of $\alpha \mathrm{R}$ over time and potential liver pathology by feeding large doses of $\alpha \mathrm{R}$ to the rats.

\section{Materials and methods}

\section{Syntheses of $\alpha$-retinyl acetate and 3,4-didehydroretinyl acetate}

$\alpha$-Retinyl acetate was synthesised using a previously described method for the synthesis of $\left[{ }^{13} \mathrm{C}\right]$ retinyl acetate ${ }^{(16)}$, except that $\alpha$-ionone (Sigma Aldrich) was substituted with $\beta$-ionone as the starting reagent and ${ }^{13} \mathrm{C}$ was not added. 3,4-Didehydroretinyl acetate was synthesised using previously published methods ${ }^{(17)}$ and stored at $-70^{\circ} \mathrm{C}$ until use. The synthesised acetate esters were purified $(>95 \%)$ on $8 \%$ water-deactivated neutral $\mathrm{Al}_{2} \mathrm{O}_{3}$ using hexanes and diethyl ether. The purity of both the compounds was confirmed by TLC, UV-visible spectrophotometry and HPLC equipped with photodiode array detection.

\section{Animals and diet}

Animal use was approved by the University of Wisconsin (UW)Madison Animal Care and Use Committee, and all animal procedures were carried out by adhering to the Public Health Service Policy on Humane Care and Use of Laboratory Animals. The facilities of the UW College of Agriculture and Life Sciences are AAALAC (Association for Assessment and Accreditation of Laboratory Animal Care) accredited and frequently inspected internally and externally to ensure compliance. The rats ( $n$ 98) were housed individually on aspen bedding in a temperatureand humidity-controlled environment under a $12 \mathrm{~h}$ light $-12 \mathrm{~h}$ dark cycle. Shaven aspen wood was chosen as bedding as it absorbs moisture, eliminates odour and has low nutritional value. Maize cobs, which are another option, would have interfered with this bioassay due to kernel contamination. Upon arrival to the laboratory, the rats were fed a vitamin A-free purified diet ad libitum ${ }^{(18)}$. The vitamin A-deficient diet (TD 04 175; Harlan-Teklad) contained the following (in $\mathrm{g} / \mathrm{kg}$ diet): casein (200); DL-methionine (3); sucrose (280); maize starch (215); maltodextrin (150); cellulose (50); soyabean oil (55); mineral mix AIN-93G TD 94046 (35); calcium phosphate (3.2); vitamin mix without added A, D, E and choline TD 83171 (5); vitamin $\mathrm{D}_{3}$ (0.0044); vitamin E (0.242); choline dihydrogen citrate (3.5); tert-butylhydroquinone (TBHQ) (0.01).

\section{Study 1}

Rats were chosen for this study because they are a defined model for growth assays and could quickly be made vitamin A deficient as they are born with low stores. For the biopotency study, 21-d-old weanling male Sprague-Dawley rats ( $n$ 40) (Charles River) were fed a vitamin A-deficient diet and weighed daily for the duration of the study. At the beginning 
of week 9, the rats were divided into four weight-matched treatment groups ( $n$ 10/group) and orally dosed with $50 \mathrm{nmol}$ retinyl acetate $(14.3 \mu \mathrm{g} \mathrm{ROH}), \alpha$-retinyl acetate $(14.3 \mu \mathrm{g} \alpha \mathrm{R})$, 3,4-didehydroretinyl acetate (14.2 $\mu \mathrm{g}$ DR) or plain cottonseed oil vehicle (negative control group). All the doses were administered in $100 \mu \mathrm{l}$ cottonseed oil. This dose $(50 \mathrm{nmol})$ was chosen because it maintains vitamin A balance in male rats $^{(15,19,20)}$. The daily dosing regimen was continued until most of the rats in the control group had abnormal secretions around the eyes and $20 \%$ of these were showing severe signs of vitamin A deficiency (i.e. scruffy coat and swollen ankles). All the rats were killed 5 weeks after the start of supplemental dosing, and tissue samples were collected. Aliquots of serum and weighed samples of liver, kidney, spleen and lung were analysed for $\mathrm{ROH}, \alpha \mathrm{R}$ and DR by HPLC.

\section{Serum analyses}

Serum was analysed using a published procedure ${ }^{(9)}$ with a slight modification. The internal standard C23 alcohol, a synthesised $\beta$-apo-carotenol ${ }^{(9)}$ (Fig. 1), was added to $500 \mu \mathrm{l}$ serum, and an equal volume of ethanol with $0 \cdot 1 \%$ butylated hydroxytoluene was added to the sample. The sample was extracted three times with $1 \mathrm{ml}$ hexane. Supernatant fractions were pooled and dried under Ar. The extract was reconstituted in $100 \mu \mathrm{l}$ methanol-dichloroethane (50:50, v/v), and $50 \mu \mathrm{l}$ were injected into the HPLC system. The isocratic HPLC system included a guard column, a Waters Symmetry ${ }^{\circledR}$ C18 column $(3.5 \mu \mathrm{m}, 4.6 \times 75 \mathrm{~mm})$, a Waters Resolve $^{\mathrm{TM}}$ C18 column $(5 \mu \mathrm{m}, 3.9 \times 300 \mathrm{~mm})$, a Rheodyne injector, a Shimadzu SPD-10A UV-VIS detector, a Waters Delta 600 pump and controller, and a Shimadzu C-R7A Plus data processor. The mobile phase was acetonitrile-water $(87 \cdot 5: 12 \cdot 5, \mathrm{v} / \mathrm{v})$ with $10 \mathrm{~mm}$-ammonium acetate as a modifier at a flow rate of $0.7 \mathrm{ml} / \mathrm{min}$.

\section{Rat tissue analysis}

Liver, kidney, lung and spleen samples were analysed using published methods ${ }^{(9,18,21)}$ with a minor modification. Tissue samples $(0.5 \mathrm{~g})$ were ground with sodium sulphate $(1.5 \mathrm{~g})$ in a mortar. Purified $\mathrm{C} 23$ alcohol was added to determine the extraction efficiency. The tissue samples were extracted repeatedly with dichloromethane to $10 \mathrm{ml} ; 5 \mathrm{ml}$ were dried under Ar. The film was redissolved in $0.75 \mathrm{ml}$ ethanol and saponified with $0.4 \mathrm{ml}$ potassium hydroxide-water (50:50, $\mathrm{w} / \mathrm{v}$ ) at $45^{\circ} \mathrm{C}$ for $30 \mathrm{~min}$. The reaction was quenched with $0.5 \mathrm{ml}$ water. The solution was extracted three times with $0.5 \mathrm{ml}$ hexane. The hexane layers were pooled, washed with $0.5 \mathrm{ml}$ water and dried under Ar. The film was redissolved in $100 \mu \mathrm{l}$ methanol-dichloroethane $(50: 50, \mathrm{v} / \mathrm{v})$ for the liver samples and $200 \mu \mathrm{l}$ for the kidney, lung and spleen samples. An aliquot of $50 \mu \mathrm{l}$ was injected into the HPLC system for the liver samples and that of $25 \mu$ l for the other tissue samples. The Waters HPLC system included the columns described above and a Waters 1525 binary HPLC pump, a 717 autosampler and a 996 photodiode array detector. The mobile phase was the same as that mentioned above, but the flow rate was $0.8 \mathrm{ml} / \mathrm{min}$. The results obtained for tissue vitamin A are reported as those for 'retinol', which included retinol and retinyl esters because tissues were saponified.

\section{Study 2}

For the interaction study, 21-d-old weanling male SpragueDawley rats $(n$ 40) were fed a vitamin A-deficient diet for 2 weeks. The rats were divided into four treatment groups ( $n$ 10/group). To allow for some liver $\mathrm{ROH}$ storage, in this study, a dose of $\mathrm{ROH}$ higher than that used in study 1 was used (i.e. $70 \mathrm{nmol}$ as retinyl acetate), which has resulted in adequate liver reserves over time in prior studies ${ }^{(18,22)}$. Each group was orally dosed with $70 \mathrm{nmol} \mathrm{ROH} / \mathrm{d}$ and $0,17 \cdot 5,35$ or $70 \mathrm{nmol}$ $\alpha \mathrm{R}$ (as $\alpha$-retinyl acetate) daily. Doses were administered in $100 \mu \mathrm{l}$ cottonseed oil. All the rats were killed 3 weeks after the start of dosing, and tissues were collected. Serum and liver samples were analysed using the procedures used in study 1.

\section{Study 3}

For the toxicity study, 21-d-old weanling male Sprague-Dawley rats $(n 18)$ were vitamin A-depleted for 3 weeks and then given $3.5 \mu \mathrm{mol} \alpha$-retinyl acetate/d dissolved in cottonseed oil or cottonseed oil alone (control) for $21 \mathrm{~d}$. The rats $(n 5)$ were killed on days 1,8 and 15 after the administration of the final dose. The control rats ( $n$ 3) were killed on day 1 . Serum, liver and kidney samples were collected at each time point. Serum samples collected from both the control and $\alpha \mathrm{R}$ groups were analysed for biochemical indicators of liver toxicity, which included K, urea, albumin, alkaline phosphatase, alanine aminotransferase, $\boldsymbol{\gamma}$-glutamyltransferase, cholesterol and total bilirubin from a routine chemistry panel. Histological sections of livers were analysed using haematoxylin and eosin stain by the UW School of Medicine and Public Health. Serum analyses were carried out by the UW Veterinary Medical Teaching Hospital Pathology Services.

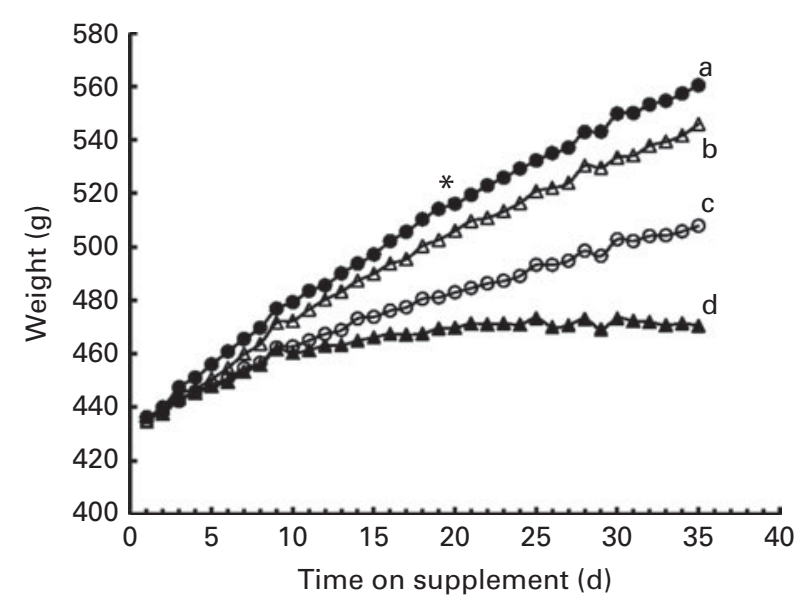

Fig. 2. Growth assay in groups of rats ( $n$ 10/group) dosed with $50 \mathrm{nmol} / \mathrm{d}$ of $\alpha$-retinol $(\bigcirc), 3,4$-didehydroretinol $(\bullet)$ or retinol $(\Delta)$ compared with a negative control $(\boldsymbol{\Lambda}$, oil) group. Using a test of effect sizes, body weights were found to differ on day 19 after the start of supplementation (denoted by *). The AUC values for growth response differed between the groups. ${ }^{a, b, c, d}$ Values with unlike letters were significantly different $(P<0.05)$. 


\section{Statistical analysis}

Animal data were analysed using the Statistical Analysis System software (SAS Institute, Inc., version 9.1, 2002-3). The outcomes of interest (i.e. rat weights and serum and tissue $\mathrm{ROH}, \alpha \mathrm{R}$ and DR concentrations) were evaluated using ANOVA. A test of effect slices was used to determine the day the body weights were different among the groups. The AUC values for bodyweight change were calculated by trapezoidal approximation. Values are presented as means and standard deviations. Significance was assessed at $\alpha<0.05$.

\section{Results}

\section{Study 1}

Body weights and weight changes. After the start of dosing, group differences in body weight approached significance $(P=0.054)$, and the day main effect and the group $\times$ day interaction were significant (both $P<0 \cdot 0001$ ). Using a test of effect sizes for group and day, the difference among the groups was found on day 19, and this was observed until the end of the dosing period (Fig. 2). The final body weights did not differ between the ROH and DR groups, but were lower in the $\alpha \mathrm{R}$ and control groups. Interestingly, liver weights were the same in the ROH (19.1 (SD 2.1) g) and DR (20.0 (SD 2.5) g) groups, but were higher than those in the $\alpha \mathrm{R}$ (14.6 (SD 1.5) g) and control (13.3 (SD 1.6) g) groups, which did not differ from each other. Kidney weights were highest in the ROH group $(3.44(\mathrm{SD} 0.28) \mathrm{g}$ ), which differed from the control (3.07 (SD 0.17) g) and DR (3.06 (SD 0.49) g) groups but did not differ from the $\alpha \mathrm{R}$ group (3.32 (SD 0.4) g). Kidney weights did not differ among the $\alpha$ R, DR and control groups.

Organ retinol concentrations. All the rats in study 1 were severely vitamin A deficient (defined as $<70 \mathrm{nmol} \mathrm{ROH} / \mathrm{g}$ liver $)^{(19)}$. Despite adequate serum $\mathrm{ROH}$ concentrations in the ROH group (1.37 (SD 0.21) $\mu \mathrm{mol} / \mathrm{l}$ ), liver reserves were fourteen times less than this deficiency cut-off (Table 1; Fig. 3), and the kidney had seven times more $\mathrm{ROH}$ than the liver. In fact, in all the treatment groups, kidney $\mathrm{ROH}$ concentrations were higher than liver $\mathrm{ROH}$ concentrations by five to ten times. Although the same amounts of treatment compounds were fed to the rats, more $\mathrm{ROH}$ was stored in the ROH group compared with DR and $\alpha \mathrm{R}$ in the $\mathrm{DR}$ and $\alpha \mathrm{R}$ groups, respectively. $\mathrm{ROH}$ was not detected in the lung and spleen of the control, $\mathrm{DR}$ and $\alpha \mathrm{R}$ groups, which supports the findings of prior work $^{(21,23)}$. DR was detected only in the tissue samples of the DR group that were analysed and $\alpha \mathrm{R}$ was detected only in those of the $\alpha \mathrm{R}$ group.

Much lower concentrations of $\mathrm{DR}$ and $\alpha \mathrm{R}$ were detected in the liver, kidney, spleen and lung of the DR and $\alpha \mathrm{R}$ groups, respectively, compared with $\mathrm{ROH}$ concentrations in the $\mathrm{ROH}$ group, suggesting an increased utilisation or impaired uptake of these analogues (Table 1).

Serum concentrations. The rats in the $\mathrm{ROH}$ group were able to maintain an adequate serum $\mathrm{ROH}$ concentration (1.37 (SD 0.21) $\mu \mathrm{mol} / \mathrm{l})$ when fed $50 \mathrm{nmol} / \mathrm{d}$. Serum $\mathrm{ROH}$ was detectable but deficient $(<0 \cdot 10 \mu \mathrm{mol} / \mathrm{l})$ in the control,

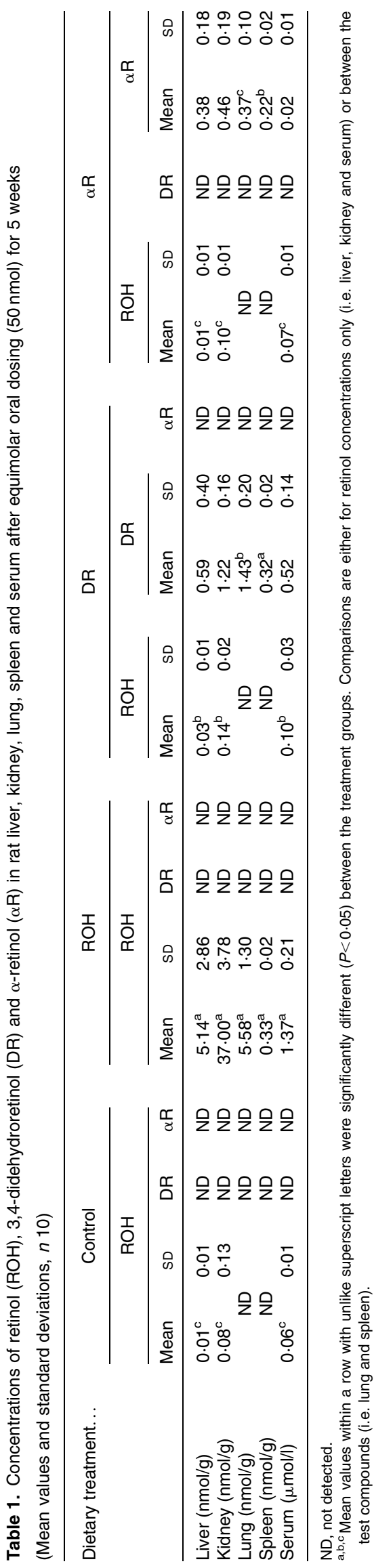




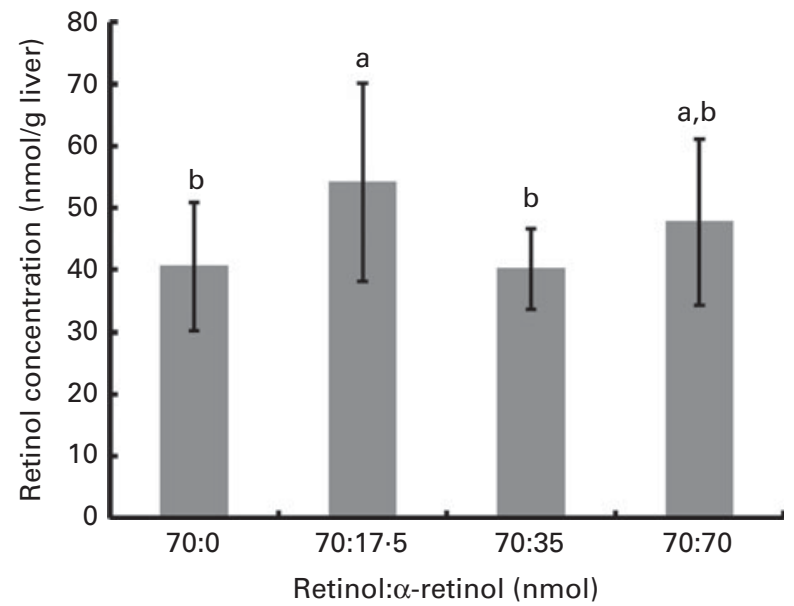

Fig. 3. Liver retinol concentrations for each group of rats ( $n$ 10/group) supplemented with different ratios of $\alpha$-retinol:retinol. Each group was orally dosed with $70 \mathrm{nmol}$ retinol/d (as retinyl acetate) and $0,17.5,35$ or $70 \mathrm{nmol}$ $\alpha$-retinol (as $\alpha$-retinyl acetate). ${ }^{a, b}$ Values with unlike letters were significantly different $(P<0.05)$.

DR and $\alpha$ R groups. Serum $\mathrm{ROH}$ concentrations were slightly higher in the DR group than in the control and $\alpha \mathrm{R}$ groups $(P<0.05)$, which may indicate a sparing effect, considering that the serum DR concentration was high (0.52 (SD 0.14) $\mu \mathrm{mol} / \mathrm{l})$. Serum $\alpha \mathrm{R}$ concentrations were measurable but low in the $\alpha \mathrm{R}$ group.

Bioactivity. In the classic growth assay, the $\alpha \mathrm{R}$ group maintained about $50 \%$ of the growth rate of the $\mathrm{ROH}$ group and the DR group maintained $>100 \%$ of that of the $\mathrm{ROH}$ group (Table 2). Bioactivity was calculated by two methods. In the first, a simple comparison of the final body weights of the control and $\mathrm{ROH}$ groups was made. In the second, AUC values were computed, and the values of the control group were subtracted from those of the treatment groups, and these values were compared with those of the $\mathrm{ROH}$ group to obtain a percentage difference. The AUC values of all the groups differed (Table 2). Similar values for bioactivity (i.e. within 8-12\%) were obtained using both the mathematical methods (Table 2).

\section{Study 2}

The final body weights of rats in study $2(345 \cdot 1$ (SD 20.4) g) did not differ among the groups and nor did the liver weights
(16.2 (sD 1.6) g). Despite adequate serum ROH concentrations (1.21 (SD 0.07) $\mu \mathrm{mol} / \mathrm{l}$ ), which did not differ among the groups, $\alpha \mathrm{R}$ was undetectable. On the other hand, liver $\mathrm{ROH}$ concentrations did differ among the groups $(P=0 \cdot 042)$; although when corrected for total liver weight, only the difference in total liver $\mathrm{ROH}$ concentrations approached significance $(P=0 \cdot 07)$. Liver $\mathrm{ROH}$ concentrations were highest in the group that received the lowest dose of $\alpha \mathrm{R}$, which did not differ from the group that received the highest dose. As anticipated, liver $\alpha \mathrm{R}$ concentrations responded in a dosedependent manner (i.e. 262 (SD 34), 449 (SD 23) and 893 (sD 138) $\mathrm{nmol} /$ liver for the $17 \cdot 5,35$ and $70 \mathrm{nmol} / \mathrm{d}$ doses, respectively; $P<0.0001)$. These represent total dose liver retentions of $71 \cdot 3,61 \cdot 1$ and $60 \cdot 7 \%$, respectively.

\section{Study 3}

No toxicity was evident in the $\alpha \mathrm{R}$ group compared with the control group after $21 \mathrm{~d}$. No stellate cell hypertrophy (Fig. 4) or increases in serum markers of liver toxicity were detected (Table 3). Liver and kidney $\alpha \mathrm{R}$ concentrations decreased quickly between day 1 and day 8, but did not change on day 15 (Table 4).

\section{Discussion}

In the 1950s, the estimates of bioactivity for $\alpha \mathrm{R}$ and $\mathrm{DR}$ in rats were 2 and $40 \%$ that for $\mathrm{ROH}$, respectively. Bioactivities of 40-50 and 120-130\% were demonstrated for $\alpha \mathrm{R}$ and DR, respectively, in the same animal model using an equimolar feeding approach. Large doses of $\alpha \mathrm{R}$ were given in prior studies; therefore, sustained chylomicron delivery from repeated dosing to replenish the tissues with small amounts did not occur. Thus, most of the dose was shunted to the liver and not recirculated to meet tissue needs because of the inability of $\alpha \mathrm{R}$ to bind to the RBP. The data reported herein on $\alpha \mathrm{R}$ are consistent with the finding reported by Clamon et $a l^{(24)}$ that $\alpha$-retinyl acetate sustains the growth of hamsters when given intraperitoneally. In prior studies with DR, the preparation was isolated from crude fish liver oil and a distilled fraction in oil was fed to the rats ${ }^{(25)}$. Therefore, it is difficult to discern exactly how much 3,4-didehydroretinyl ester was fed during that $28 \mathrm{~d}$ study, because only the amount of oil fed was measured and reported. The preparations used in the present study were chemically synthesised and carefully

Table 2. Comparison of bioactivities of $\alpha$-retinol $(\alpha \mathrm{R})$ and 3,4-didehydroretinol (DR) with that of retinol (ROH)*

(Mean values and standard deviations, differences and percentages, $n 10$ )

\begin{tabular}{|c|c|c|c|c|c|c|c|c|}
\hline \multirow[b]{2}{*}{ Dietary treatment } & \multicolumn{4}{|c|}{ Final body weight $(\mathrm{g})$} & \multicolumn{4}{|c|}{ Area under the growth curve (group $\times$ day) } \\
\hline & Mean & SD & $\begin{array}{l}\text { Difference from } \\
\text { the control }(\mathrm{g})\end{array}$ & $\begin{array}{c}\text { Percentage of } \\
\mathrm{ROH}\end{array}$ & Mean & SD & $\begin{array}{l}\text { Difference from } \\
\text { the control }\end{array}$ & $\begin{array}{c}\text { Percentage of } \\
\mathrm{ROH}\end{array}$ \\
\hline Control & $470^{c}$ & $46 \cdot 2$ & 0 & 0 & $867^{d}$ & 298 & 0 & 0 \\
\hline$\alpha \mathrm{R}$ & $508^{b}$ & $34 \cdot 0$ & $37 \cdot 4$ & $49 \cdot 5$ & $1165^{c}$ & 138 & 298 & 37.9 \\
\hline DR & $560^{a}$ & $41 \cdot 8$ & $90 \cdot 0$ & 119 & $1867^{a}$ & 188 & 1000 & 127 \\
\hline $\mathrm{ROH}$ & $546^{a}$ & $36 \cdot 2$ & 75.5 & 100 & $1654^{b}$ & 273 & 787 & 100 \\
\hline
\end{tabular}

a,b,c,d Mean values within a column with unlike superscript letters were significantly different $(P<0.05)$ between the treatment groups.

${ }^{*}$ Rats were fed $50 \mathrm{nmol} / \mathrm{d}$ of the test compounds for 5 weeks. Body weights were measured daily. 


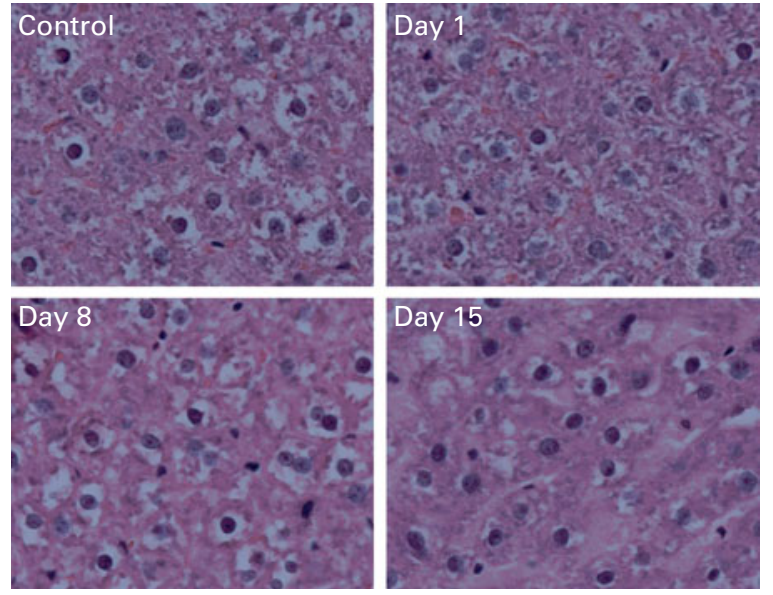

Fig. 4. Haematoxylin and eosin staining of liver sections. No hepatotoxicity was observed with $21 \mathrm{~d}$ of $\alpha$-retinyl acetate dosing $(3.5 \mu \mathrm{mol} / \mathrm{d})$. The rats were killed 1,8 and $15 \mathrm{~d}$ after the administration of the last dose.

purified, and an accurately measured amount equalised to retinyl acetate amounts known to maintain balance in rats was fed each day.

Quadro et $a l .{ }^{(26)}$ have shown that $R B P$-knockout mice survive well and exhibit little evidence of vitamin A deficiency when fed a vitamin A-adequate diet. Presumably, their extrahepatic tissues obtain enough vitamin A from retinyl esters in lipoproteins to support growth and function. This explains why $\alpha \mathrm{R}$ can support growth in rats despite its inability to bind to the RBP. $\alpha \mathrm{R}$ can be transported to tissues via chylomicrons and their remnants. It can be utilised as a tag to traffic $\mathrm{ROH}$, but it can be distinguished from $\mathrm{ROH}$ that arrives to tissues through the RBP. This concept has recently been applied to a lactating sow-nursing piglet dyad where $\alpha \mathrm{R}$ was followed from the mother to the offspring ${ }^{(27)}$. Retinol trafficking could be studied during pregnancy with $\alpha \mathrm{R}$ and without the use of RBP-deficient animals ${ }^{(28)}$.

The growth effects of vitamin A are mediated by retinoic acid via retinoic acid nuclear receptor ${ }^{(29)}$, which may indicate that the growth effect of $\alpha \mathrm{R}$ is functioning by the same mechanism. The apparent conclusion is that the analogues are oxidised to carboxylic acid analogues and that they bind to retinoid nuclear receptor proteins. This phenomenon might have implications for pharmaceutical or cosmetic applications. Due to the limited knowledge of the role of $\alpha$-retinoic acid in growth promotion, a future study to determine the interaction of $\alpha$-retinoic acid with retinoic acid nuclear receptor or perhaps retinoid $\mathrm{X}$ receptor ${ }^{(29)}$ is certainly important. 3,4-Didehydroretinoic acid is a known ligand of retinoic acid nuclear receptor- $\alpha,-\beta$ and $-\gamma$ with the same affinity as retinoic acid $^{(30)}$.3,4-Didehydroretinoic acid supports avian growth and development, and binding assays for retinoic acid nuclear receptor- $\beta$ have been found to be nearly identical for chick and mouse receptors ${ }^{(31)}$. Furthermore, at high doses of 3,4-didehydroretinyl acetate and retinyl acetate given to dams, both have been found to cause terata in foetuses but not to the extent of retinoic acid alone ${ }^{(32)}$. These data support similar bioactivities. The finding of a higher growth AUC value for DR should be investigated with 3,4-didehydroretinoic acid compared with retinoic acid in a similarly designed rat study.

Furthermore, the difference between the present study and previous work may be partly due to changes in animal feeding and care since the 1950s. Currently, animal care facilities are often sterile or near-sterile environments behind barriers. Veterinary care and personal protective equipment are commonplace. Considering the severe degree of vitamin A deficiency in the growth assay study, even a mild infection among the rats would have certainly caused death in all the groups. The normal serum ROH concentrations in the ROHtreated rats, which were severely vitamin A deficient based on liver reserves, indicate that the rats were healthy and not suffering from infection, which elicits the acute-phase response reducing serum $\mathrm{ROH}$ concentrations ${ }^{(33)}$. Moreover, diet formulations have improved over the past few decades and are more than adequate to meet nutritional requirements. Thus, co-nutrient depletion is not a confounder when a diet is designed to be single-nutrient deficient.

One of the notable improvements in the present study over those in the 1950s is that the treatment compounds were fed at equimolar amounts at a level known to keep rats (weight approximately $420 \mathrm{~g}$ ) in vitamin A balance ${ }^{(15)}$. Although this level of $\mathrm{ROH}$ resulted in very little $\mathrm{ROH}$ storage, it maintained serum $\mathrm{ROH}$ concentrations. A disadvantage of the present study is that lower doses of $\mathrm{DR}$ and $\alpha \mathrm{R}$ were not included. Future studies should investigate lower doses of each of these compounds for the maintenance of rat growth. At the end of the present study, the rats maintained on the various analogues were found to continue growing and, therefore, longer-term studies with lower doses may help to define the value of growth assays $v$. liver storage assays. Although the storage rates of the compounds were not equal and not included in the estimation of bioactivity reported herein, the severe $\mathrm{ROH}$ deficiency in the rats, even in the $\mathrm{ROH}$ group, supports a higher bioactivity than previously published for both DR and $\alpha$ R. Furthermore, extreme differences in the liver retention of $\alpha \mathrm{R}$ were observed in studies 1, 2 and 3. In study 1 , where $\mathrm{ROH}$ was not made available, only $0.3 \%$ of the cumulative $\alpha \mathrm{R}$ doses were recovered in the liver. This is

Table 3. Comparison of serum chemistry profile of rats dosed with $3.5 \mu \mathrm{mol} \alpha$-retinyl acetate/d $(n 5)$ with that of rats dosed with cottonseed oil alone (control, $n 3$ ) for $21 \mathrm{~d}$

(Mean values and standard deviations)

\begin{tabular}{|c|c|c|c|c|}
\hline \multirow[t]{2}{*}{ Dietary treatment... } & \multicolumn{2}{|c|}{ Control* $^{*}$} & \multicolumn{2}{|c|}{$\alpha$-Retinol } \\
\hline & Mean & SD & Mean & SD \\
\hline $\mathrm{K}(\mathrm{mmol} / \mathrm{l})$ & $6 \cdot 1$ & 1.42 & $5 \cdot 32$ & 0.46 \\
\hline Urea $(\mathrm{mg} / \mathrm{l})$ & 160 & $17 \cdot 3$ & 158 & $13 \cdot 0$ \\
\hline Albumin (g/l) & 34.7 & $3 \cdot 8$ & $30 \cdot 8$ & $2 \cdot 3$ \\
\hline Alkaline phosphatase (U/l) & 224 & $88 \cdot 3$ & 248 & 34.4 \\
\hline Alanine aminotransferase $(\mathrm{U} / \mathrm{l})$ & 44.3 & 9.45 & 38.0 & 4.06 \\
\hline$\gamma$-Glutamyltransferase $(\mathrm{U} / \mathrm{I})$ & $<5$ & & $<5$ & \\
\hline Cholesterol (mg/l) & 780 & 255 & 810 & 206 \\
\hline Total bilirubin $(\mathrm{mg} / \mathrm{l})$ & 8.3 & 8.5 & $6 \cdot 4$ & 3.0 \\
\hline
\end{tabular}

* Serum was collected $1 \mathrm{~d}$ after the administration of the final dose. 
in stark contrast with study 2, where $61-71 \%$ of the cumulative doses were recovered, further supporting $\alpha \mathrm{R}$ bioactivity. The huge decrease in $\alpha \mathrm{R}$ concentrations between day 1 and day 8 in study 3 supports utilisation, considering that no $\mathrm{ROH}$ was administered during this study. Liver $\mathrm{ROH}$ concentrations observed in study 2 suggest that $\alpha \mathrm{R}$ does not interfere with $\mathrm{ROH}$ in intestinal absorption and hepatic metabolism when fed at physiological levels. However, a sparing effect of ROH may have occurred at the low dose of $\alpha \mathrm{R}$ $(17.5 \mathrm{nmol} / \mathrm{d})$, which could also be used for growth as shown in study 1.

A notable limitation of the present study is that vision testing was not carried out. Nonetheless, predictions from the literature indicate that the control and $\alpha \mathrm{R}$ groups were probably night blind and 3,4-didehydroretinal probably replaced retinal in the rod cells at high serum DR concentrations. Indeed, rats maintained on DR exhibited normal retina integrity ${ }^{(34)}$. Furthermore, in human subjects fed a fishoil concentrate, night vision acuity has been shown to shift in favour of red light probably due to 3,4-didehydroretinal ( $\lambda_{\max }$ approximately $400 \mathrm{~nm}$ ) replacing retinal $\left(\lambda_{\max }\right.$ approximately $370 \mathrm{~nm}$ ) in the retina ${ }^{(35)}$.

Significant serum ROH and DR concentrations were detected in rats dosed with retinyl acetate and 3,4-didehydroretinyl acetate, respectively, which is an indication of increased recycling considering low liver storage and comparatively higher concentrations in the kidney. On the other hand, only small amounts of $\alpha \mathrm{R}$ were detected in the serum of $\alpha$-retinyl acetate-dosed rats, supporting previous reports that $\alpha \mathrm{R}$ cannot bind to the $\operatorname{RBP}^{(9,13)}$. Serum DR concentrations in the DR group were 2.6 times less than serum $\mathrm{ROH}$ concentrations in the $\mathrm{ROH}$ group in study 1 , but growth was maintained probably due to the sustained formation of 3,4-didehydroretinoic acid. Serum $\mathrm{ROH}$ concentrations drive the utilisation of $\mathrm{ROH}^{(20,36)}$. It appears that the $\mathrm{ROH}$ rats maintained a high utilisation rate even though their liver $\mathrm{ROH}$ reserves were exhausted. Furthermore, identical serum $\mathrm{ROH}$ concentrations in rats given $50 \mathrm{nmol} / \mathrm{d}$ in study 1 and those given $70 \mathrm{nmol} / \mathrm{d}$ and no $\alpha \mathrm{R}$ (data not shown) in study 2 indicate increased recycling by the kidney, given that liver concentrations in study 2 were $9 \cdot 3$ times higher than those in study 1 .

The finding that $\alpha \mathrm{R}$ did not appreciably affect $\mathrm{ROH}$ storage suggests that $\alpha \mathrm{R}$ has little influence on $\mathrm{ROH}$ metabolism at physiological doses in ratios consistent with typical dietary intake, unlike the finding that $\alpha$-carotene has a negative effect on $\beta$-carotene absorption in rats, which was measured by liver $\mathrm{ROH}$ storage ${ }^{(14)}$. If $\alpha$-carotene had been fed to the rats in study 2 , the bio potency of $\alpha \mathrm{R}$ might have differed from that demonstrated in study $1 . \alpha$-Carotene may affect $\beta$-carotene uptake earlier in the digestion process at the site of absorption or by competition at the carotenoid transporter on the apical surface of enterocytes ${ }^{(37)}$, chylomicron assembly, or competition for the 15,15-carotenoid mono-oxygenase cleavage enzyme.

Data on the bioactivity of $\alpha \mathrm{R}$ reported herein could change the calculated vitamin A value of some foods, especially orange carrots, which contain substantial amounts of $\alpha$-carotene. Currently, $\alpha \mathrm{R}$ is not considered to have vitamin $\mathrm{A}$

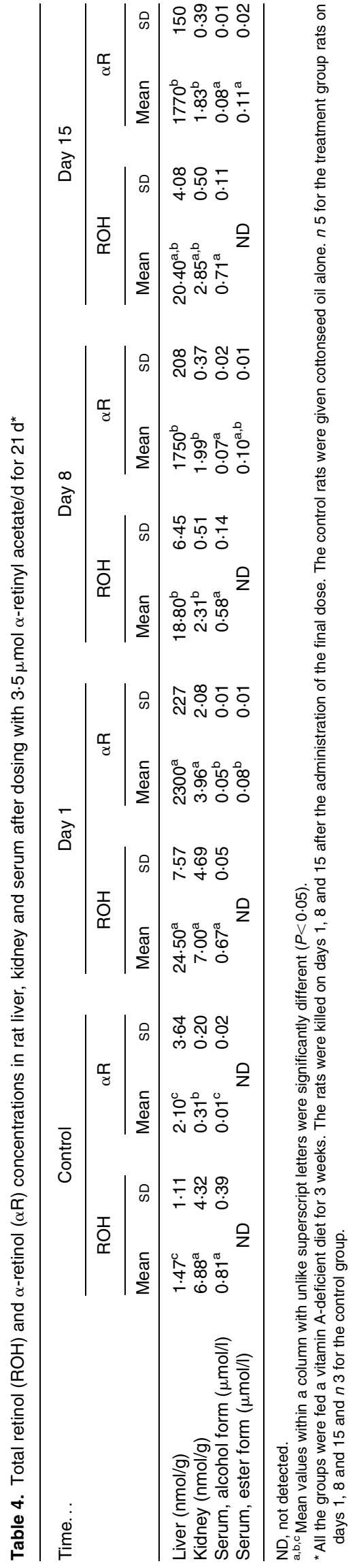


activity, yet it clearly supports growth in rats and is not toxic at moderate intakes. During vitamin A deficiency, $\alpha$, presumably through the formation of $\alpha$-retinoic acid as needed, most probably supports functions supported by retinoic acid. Thus, growth assays with $\alpha$-retinoic acid and retinoic acid should be carried out to determine the difference in bioactivities. The results obtained in the toxicity study suggest that at very high liver $\alpha \mathrm{R}$ concentrations, no hepatotoxicity occurs, but that $\alpha \mathrm{R}$ is quickly cleared. Nonetheless, at $\alpha \mathrm{R}$ concentrations $>1.7 \mu \mathrm{mol} / \mathrm{g}$ liver, significant amounts of $\alpha$-retinyl esters were found to be circulating in the blood ( $>10 \%$ of total retinol), most probably on lipoproteins. Future studies should determine at what liver $\mathrm{ROH}$ concentration this begins to occur, because liver retinyl esters $>10 \%$ of total are considered a biomarker of excessive vitamin A status in humans ${ }^{(38)}$.

\section{Acknowledgements}

The authors thank Peter Crump, UW-Madison College of Agriculture and Life Sciences Statistical Consulting Service, for statistical analysis consultation. Part of this work was presented at the Experimental Biology Meeting in 2011, Washington, DC, USA.

The present study was supported by USDA NRI 2007-35 200-17 729, the International Atomic Energy Agency's Nobel Peace Prize Fellowship Program (N. R.) and NIH Grant T32-DK007665 (J. T. D.). The funders had no role in the design and analysis of the work or in the writing of this article.

The authors' contributions are as follows: N. R. conducted the research and serum and tissue analyses, provided input for statistical analysis and wrote the first draft of the paper; J. T. D. conducted study 3; S. A. T. designed the research, provided input for the statistical analysis and revised the paper.

The authors have no conflicts of interest to declare.

\section{References}

1. Ames SR, Swanson WJ \& Harris PL (1955) Biochemical studies on vitamin A. XV. Biopotencies of geometric isomers of vitamin A aldehyde in the rat. J Am Chem Soc 77, 4136-4138.

2. Goodman DS, Smith JE, Hembry RM, et al. (1974) Comparison of the effects of vitamin $\mathrm{A}$ and its analogs upon rabbit ear cartilage in organ culture and upon growth of the vitamin A-deficient rat. J Lipid Res 15, 406-414.

3. Sneider WD, Rosso GC, Rogers AE, et al. (1974) The "partial" vitamin A function of $\alpha$-retinol. J Nutr 104, 1662-1668.

4. Pitt GAJ (1978) $\alpha$-Retinol. Wld Rev Nutr Diet 31, 65-70.

5. Pitt GAJ (1983) Chemical structure and the changing concept of vitamin A activity. Proc Nutr Soc 42, 43-51.

6. Pitt GAJ (1969) Comment on the metabolic function of vitamin A. Am J Clin Nutr 22, 1045-1046.

7. Houghton SE (1969) $\alpha$-Retinol. PhD Thesis, University of Liverpool.

8. Shantz EM \& Brinkman JH (1950) Biological activity of pure vitamin $\mathrm{A}_{2}$.J Biol Chem 183, 467-471.

9. Tanumihardjo SA \& Howe JA (2005) Twice the amount of $\alpha$-carotene isolated from carrots is as effective as $\beta$-carotene in maintaining the vitamin A status of Mongolian gerbils. J Nutr 135, 2622-2626.

10. Combs GF Jr (2007) Vitamin A. In Vitamins: Fundamental Aspects in Nutrition and Health, 3rd ed., pp. 95-144. Burlington, MA: Academic Press.

11. Mills JP, Furr HC \& Tanumihardjo SA (2008) Retinol to retinol-binding protein (RBP) is low in obese adults due to elevated apo-RBP. Exp Biol Med 233, 1255-1261.

12. Dew SE \& Ong DE (1994) Specificity of the retinol transporter of the rat small intestine brush border. Biochemistry 33, $12340-12345$.

13. Muhilal H \& Glover $\mathrm{J}$ (1975) The affinity of retinol and its analogues for retinol-binding protein. Biochem Soc Trans 3, 744-746.

14. Furusho T, Kataoka E, Yasuhara T, et al. (2000) Retinol equivalent of carotenoids can be evaluated by hepatic vitamin A content. Int J Vitam Nutr Res 2, 43-47.

15. Green MH \& Green JB (1994) Vitamin A intake and status influence retinol balance, utilization and dynamics in rats. J Nutr 124, 2477-2485.

16. Tanumihardjo SA (2001) Synthesis of $10,14,15^{-13} \mathrm{C}_{4-}$ and 14 , ${ }^{15-}{ }^{13} \mathrm{C}_{2}$-retinyl acetate. J Labelled Cpd Radiopharm 44, 365-372.

17. Tanumihardjo SA, Barua AB \& Olson JA (1987) Use of 3,4didehydroretinol to assess vitamin A status in rats. Int J Vitam Nutr Res 57, 127-132.

18. Escaron AL, Green MH \& Tanumihardjo SA (2009) Plasma turnover of 3,4-didehydroretinol (vitamin $\mathrm{A}_{2}$ ) increases in vitamin A-deficient rats fed low versus high dietary fat. J Lipid Res 50, 694-703.

19. Adams WR \& Green MH (1994) Prediction of liver vitamin A in rats by an oral isotope dilution technique. J Nutr $\mathbf{1 2 4}$, 1265-1270.

20. Kelley SK \& Green MH (1998) Plasma retinol is a major determinant of vitamin A utilization in rats. $J$ Nutr $\mathbf{1 2 8}$, 1767-1773.

21. Sun T, Surles RL \& Tanumihardjo SA (2008) Vitamin A concentrations in piglet extrahepatic tissues respond differently ten days after vitamin A treatment. J Nutr 138, 1101-1106.

22. Tanumihardjo SA (2000) Vitamin A status assessment in rats using ${ }^{13} \mathrm{C}_{4}$-retinyl acetate and gas chromatography-combustion isotope ratio mass spectrometry (GCCIRMS). J Nutr $\mathbf{1 3 0}$, 2844-2849.

23. Ross AC \& Li N (2007) Lung retinyl ester is low in young adult rats fed a vitamin A-deficient diet after weaning, despite neonatal vitamin A supplementation and maintenance of normal plasma retinol. J Nutr 137, 2213-2218.

24. Clamon GH, Sporn MB, Smith, et al. (1974) $\alpha$ - and $\beta$-Retinyl acetate reverse metaplasias of vitamin A deficiency in hamster trachea in organ culture. Nature 250, 64-66.

25. Jensen JL, Shantz EM, Embree ND, et al. (1943) The biological activity of vitamin $\mathrm{A}_{2}$. J Biol Chem 149, 473-477.

26. Quadro L, Blaner WS, Salchow DJ, et al. (1999) Visual defect and impaired retinoid availability in mice lacking retinolbinding protein. EMBO J 18, 4633-4644.

27. Dever JT, Surles RL, Davis CR, et al. (2011) $\alpha$-Retinol is distributed through serum retinol-binding protein-independent mechanisms in the lactating sow-nursing piglet dyad. J Nutr 141, 42-47.

28. Quadro L, Hamberger L, Gottesman ME, et al. (2004) Transplacental delivery of retinoid: the role of retinol-binding protein and lipoprotein retinyl ester. Am J Physiol Endocrinol Metab 286, E844-E851. 
29. De Lera AR, Bourguet W, Altucci L, et al. (2007) Design of selective nuclear receptor modulators: RAR and RXR as a case study. Nature Rev Drug Discov 6, 811-820.

30. Sani BP, Venepally PR \& Levin AA (1997) Didehydroretinoic acid: retinoid receptor-mediated transcriptional activation and binding properties. Biochem Pharmacol 53, 1049-1053.

31. Repa JJ, Plum LA, Tadikonda PK, et al. (1996) All-trans 3,4-didehydroretinoic acid equals all-trans retinoic acid in support of chick neuronal development. FASEB $J \mathbf{1 0}$, 1078-1084.

32. Duitsman PK \& Olson JA (1996) Comparative embryolethality and teratogenicity of the all-trans isomers of retinoic acid, 3,4-didehydroretinyl acetate, and retinyl acetate in pregnant rats. Teratology 53, 237-244.

33. Tanumihardjo SA (2011) Vitamin A: biomarkers of nutrition for development. Am J Clin Nutr 94, S658-S665.
34. Howell JM, Thompson JN \& Pitt GAJ (1967) Reproduction and vision in rats maintained on a retinol-free diet containing 3-dehydroretinol (vitamin $\mathrm{A}_{2}$ ). Br J Nutr 21, 373-376.

35. Millard EB Jr \& McCann WS (1949) Effect of vitamin $A_{2}$ on the red and blue threshold of fully dark adapted vision. J Appl Physiol 1, 807-810.

36. Green MH, Green JB \& Lewis KC (1987) Variation in retinol utilization rate with vitamin A status in the rat. $J$ Nutr 117, 694-703

37. During A, Dawson HD \& Harrison EH (2005) Carotenoid transport is decreased and expression of the lipid transporters SR-BI, NPC1L1, and ABCA1 is downregulated in Caco-2 cells treated with ezetimibe. J Nutr 135, 2305-2312.

38. Penniston KL \& Tanumihardjo SA (2006) The acute and chronic toxic effects of vitamin A: a review. Am J Clin Nutr 83, 191-201. 